\title{
Efectividad de los derechos humanos en jaque: arbitrajes de inversiones en el marco del COVID-19
}

POR JAVIER ECHAIDE $\left(^{*}\right)$

Los derechos que dependen de la propiedad son los más precarios. Paine (1737-1809)(**)

Sumario: I. Introducción.- II. El contexto previo.- III. Situación con el ISDS en materia de inversión.- IV. La tormenta perfecta.- V. Tres preguntas.- VI. Cuando los derechos humanos dependen de los recursos.- VII. Conclusión.- VIII. Bibliografía.

Resumen: el marco de la pandemia global por el COVID-19 ha alterado la vida de miles de millones de personas, pero también ha generado uno de los mayores impactos en la historia internacional reciente en materia sanitaria, con aproximadamente 4.22 millones de personas fallecidas (Our World In Data, 26/09/2021b) y más de 206 millones de personas infectadas desde el inicio de la pandemia al 26 de septiembre de 2021 (Our World In Data, 26/09/2021a). Sin embargo, la pandemia hace relucir las condiciones que ya eran preexistentes y que reflejan la desigualdad con la que países enteros, sociedades, individuos y clases sociales pueden hacer frente a esta amenaza global. En este marco de crisis, las empresas multinacionales ya están amenazando a distintos Estados en la región y fuera de ella a entablar demandas ante organismos de arbitraje internacional a fin de reclamar la protección de sus inversiones en contra de las medidas tomadas por los diferentes gobiernos en el mundo para contener la propagación del COVID-19. La presentación versará sobre cómo el sistema de solución de controversias inversorEstado va a ser una versión más de la crisis provocada por la pandemia global, y cómo ello profundizará la crisis quitando recursos públicos que podrían utilizarse para sostener los sistemas sanitarios y las economías nacionales, incrementando así las desigualdades en vez de ayudar a resolverlas.

Palabras claves: CIADI - inversiones - derechos humanos - COVID-19

$(*)$ Dr. en Derecho, Universidad de Buenos Aires (UBA). Abogado, Universidad de Buenos Aires (UBA). Esp. en Derecho Internacional. Investigador Adjunto del CONICET e Investigador del Instituto de Investigaciones Jurídicas y Sociales Ambrosio L. Gioja, Facultad de Derecho (UBA). Prof. de la Universidad de Buenos Aires y de la Universidad Nacional de Lomas de Zamora (UNLZ).

(**) Citado por Paul Kelly (2014, p. 134). 


\section{Effectiveness of human and social rights in check: Investment arbitrations under COVID-19 framework}

Abstract: the framework of the global pandemic due to COVID-19 has altered the lives of billions of people, but it has also generated one of the greatest health impacts in recent international history, with more than a million people dead and 32 one billion people infected. However, the pandemic highlights the conditions that were already pre-existing and that reflect the inequality with which entire countries, societies, individuals and social classes can cope with this global threat. In this context of crisis, multinational companies are already threatening different States in the region and outside of it to file lawsuits before international arbitration bodies in order to demand the protection of their investments against the measures taken by the different governments in the world to contain the spread of COVID-19. The presentation will deal with the investor-State dispute settlement system, which will be one more version of the crisis caused by the global pandemic, and how this will deepen the crisis by removing public resources that could be used to sustain health systems and national economies. thus increasing inequalities rather than helping to solve them.

Keywords: ICSID - investments - human rights - COVID-19

\section{Introducción}

Thomas Paine (1737-1809) es conocido por ser el autor de El Sentido Común (Common Sense), un folleto de 48 páginas publicado en 1776 - mismo año en que se publicó La Riqueza de las Naciones de Adam Smith - con una clara intención de intervención política, y con éxito: fue uno de los panfletos de mayor influencia durante la Guerra de Independencia de los EE.UU. Claro que con la frase que referimos en este texto, él se refería a los derechos políticos: si la capacidad de sufragio dependía de la condición social - es decir, la de propietario, la de acaudalado, la de ser de clase alta, o lo que fuere-, ese derecho resultaba ser un derecho frágil. Perdida la condición (porque la posición social puede perderse), el derecho habría de desvanecerse, con lo cual no nos encontrábamos frente a un verdadero derecho.

Pero los derechos no se quedaron en los llamados "de primera generación". El derecho fue evolucionando y sumando más derechos subjetivos: a los derechos individuales marcados por la no intervención de las autoridades se les sumaron los derechos sociales caracterizados por la acción del Estado, y luego de estos otros tantos más que multiplicaron las "generaciones" de derechos que les siguieron. Muchos de todos estos derechos subjetivos hoy los consideramos como "derechos fundamentales" sin discusión. Se plasman en las constituciones políticas y figuran en tratados internacionales de derechos humanos. Forman "núcleos duros" sobre 
los que montamos nuestras vidas y celebramos nuestro "pacto social" con nuestros congéneres. Nos resulta tan básico esto como el paisaje.

No obstante, la frase de Paine es tan actual como hace 244 años. Como bien lo demostraron Stephen Holmes y Cass Sunstein (2011), todos los derechos (individuales, sociales, de lra generación, de 2da, o de cualquier otra) incurren en costos que el Estado y la sociedad deben asumir para poder ejercerse. Y lo hacen con beneplácito porque forma parte de lo que queremos ser.

¿Qué pasaría si, al depender de las condiciones económicas, los derechos fueran "desfinanciados"? Paine nos resuena en la cabeza, pues si los derechos dependen de los recursos disponibles, un escenario de recursos cada vez más escasos equivaldría a cada vez menos derechos. Por supuesto que ello contraviene al principio de progresividad, pero pone además en aprietos la versión más vieja y clásica de la razón de Estado. Lejos de la visión de Marx de disolver un Estado que mantiene las diferencias de clase y, en un comunismo donde las clases no existan más el Estado se disolvería, esta visión volvería superfluo al Estado como garante de derechos en tanto cada vez habría menos por carencia de recursos. Es una visión regresiva, no solo jurídicamente regresiva sino históricamente. Un regreso al estado de naturaleza, sin Estado, pero también sin derechos.

Por supuesto que el sostenimiento de los derechos requiere del compromiso económico del Estado. La palabra clave para entender aquí es el "depende", pues ello refleja una relación de servicio de los derechos a la economía o de la economía a los derechos.

\section{El contexto previo}

La pandemia global por el coronavirus COVID-19 irrumpió a inicios de 2020 sobre una realidad ya existente. El resultado inmediato de la pandemia no fue alterar esas realidades sino aflorarlas. El teletrabajo ya existía, aunque marginalmente: las restricciones a la movilidad, adoptadas para contener la propagación del coronavirus, hicieron que todos quienes pudiéramos trabajar remotamente lo hiciéramos, descubriendo (o quizás redescubriendo) la importancia de los lugares presenciales de trabajo para quienes lo hacemos en los ámbitos académicos (docentes y estudiantes), a contrario sensu de lo que muchos podían suponer. Quienes ya trabajaban en condiciones precarias, o se quedaron sin trabajo o se precarizaron aún más. Quienes eran pobres, lo siguen siendo o deterioraron aún más su realidad. Y donde había desigualdad, ahora hay más desigualdad.

El COVID-19 no inventó las cosas, simplemente le sacó lustre. La desigualdad existente a nivel planetario ya expresaba que, según un informe del Credit Suisse de 2019 , el $43,9 \%$ de la riqueza socialmente generada estaba en manos del $0,9 \%$ 
de la población mundial, mientras que el $56,6 \%$ de los habitantes del planeta solo tienen un 1,8\% de esa riqueza (Credit Suisse, 2019). Esta desigualdad social no fue causada por la pandemia, pero sin dudas que el COVID-19 no vino a resolverla. Se trata del contexto y sobre este la pandemia actúa acentuando debilidades y profundizando las necesidades.

\section{Gráfico 1: Pirámide global de la riqueza}

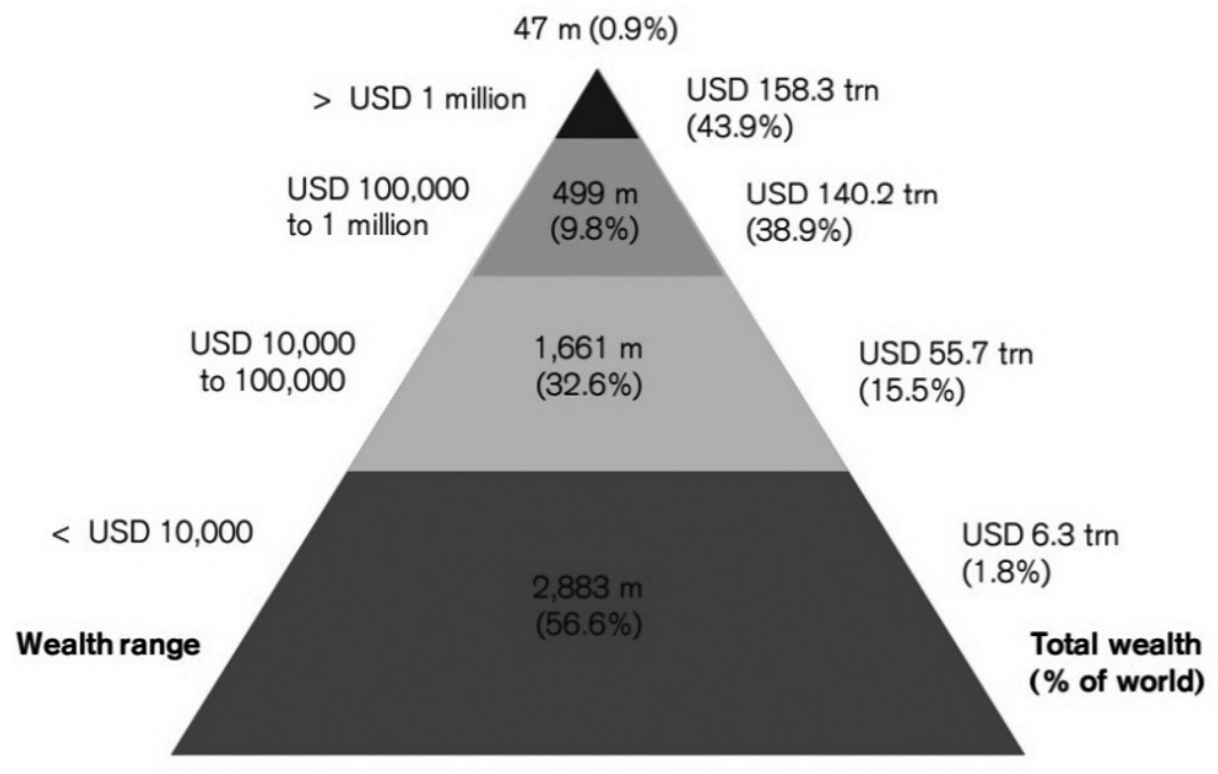

Number of adults (percent of world adults)

Fuente: Credit Suisse (2019, p. 9).

Hay entonces un problema de contexto que es previo a la pandemia de COVID-19. En ese contexto donde la desigualdad es cada vez más preocupante, también se incrementan brechas preexistentes y cada vez más pronunciadas entre la acumulación del capital público y del capital privado a escala global. El capital privado es cada vez mayor mientras que los Estados se encuentran cada vez más desfinanciados. De las cien economías más grandes del mundo, el 40\% son empresas privadas, a punto tal que el capital de muchas de ellas se mide de igual a igual con los PBI de muchos Estados medianos, incluso países desarrollados: la transnacional holandesa Shell se mide a la par que la economía de Irán, o Walmart resulta ser una economía más grande que el PBI de toda la Argentina (TNI, 2014). 


\section{Gráfico 2: Países cada vez más ricos, pero gobiernos cada vez más pobres}

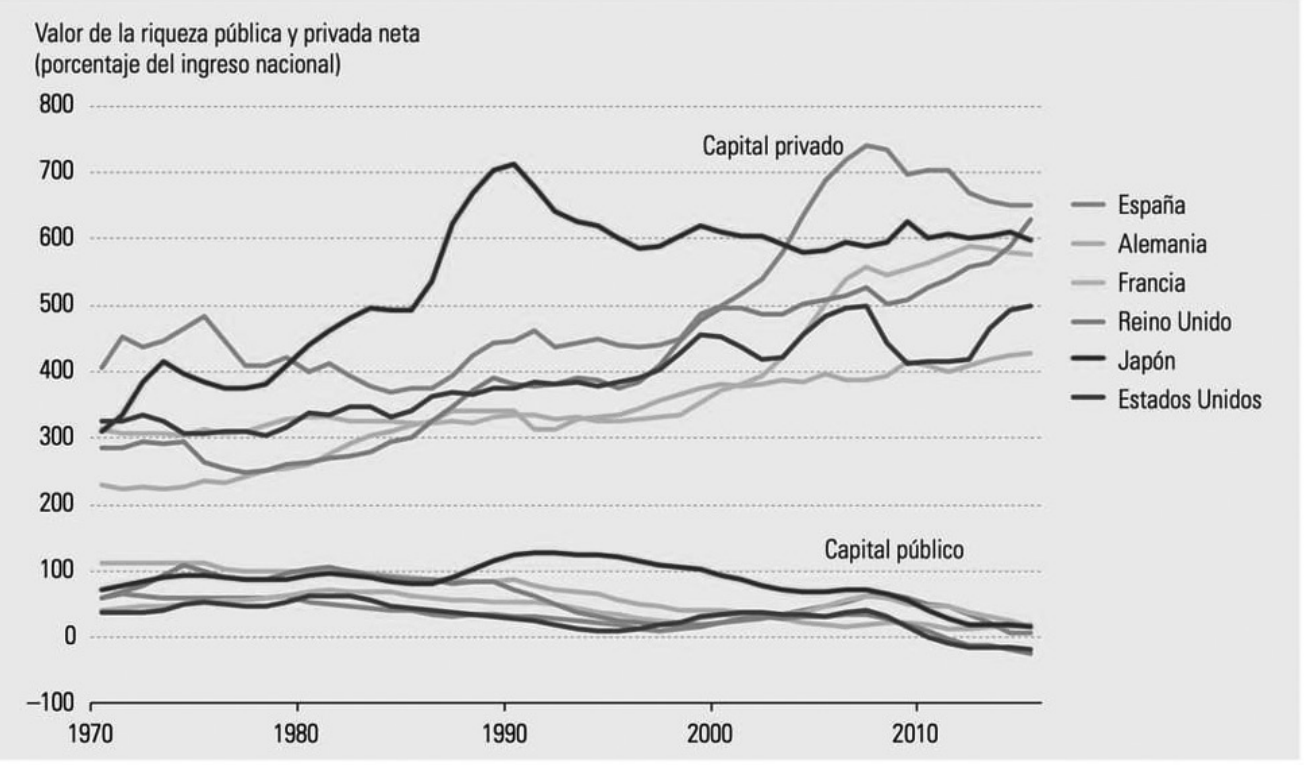

Fuente: Confederación Sindical Internacional (CSI) (2020, p. 13).

¿Cómo ha ocurrido esto? El salto ha ocurrido en los últimos treinta años, aunque viene ocurriendo desde la década de 1970. A partir de dicha década, las principales empresas comienzan a expandirse internacionalizando sus operaciones. A partir de 1991, con la implosión de la URSS, los mercados de Europa Oriental se abren para las empresas privadas occidentales, lo cual coincide también con el auge de un proceso de privatizaciones en América Latina que venía dando incipientes ensayos desde 1973, tras el Golpe de Estado en Chile o el de 1976 en Argentina. A partir de la década de 1990, el capital privado se expande globalmente en este contexto que llamamos globalización, y lo hace protegido por Estados mediante la firma de Tratados Bilaterales de Inversión (TBI) (Estévez Araujo, 2021), acuerdos bilaterales entre Estados de texto amplio, con cláusulas vagas y cuya finalidad es revestir de protección al capital privado extranjero para "generar las condiciones" para atraer dicha inversión y potenciar el crecimiento, la creación de empleos y la disminución de la pobreza. Prácticamente todos los preámbulos de los TBI, así como los fundamentos de las leyes locales que los aprobaron, abundan en este tipo de argumentaciones, y el caso argentino es claro testigo de ello (Arroyo Picard y Ghiotto, 2017).

\section{Situación con el ISDS en materia de inversión}

Argentina ha firmado 61 de estos tratados desde el 22 de mayo de 1990, fecha en que suscribió su primer TBI con Italia. De esos 61 TBI firmados posee actualmente 
en vigor 49, 6 de ellos fueron terminados (India, Bolivia, Sudáfrica y Ecuador los denunciaron unilateralmente en 2013, 2014, 2017 y 2018, respectivamente; Indonesia lo terminó de mutuo consentimiento con Argentina en 2016; y el TBI con Chile fue reemplazado por el tratado de libre comercio - TLC - celebrado en 2019), y otros 6 TBI (con Nueva Zelanda, Grecia, República Dominicana, Qatar, Emiratos Árabes y Japón) aún no han entrado en vigor (UNCTAD, 2020a). Argentina es el país que más TBI ha celebrado en la región, más que Chile (55), casi el doble más que Uruguay (36), México (35) o Perú (33), muchos más que Paraguay (26), y más del triple que Colombia (19). Incluso tiene más TBI que Estados Unidos (47) o Canadá (45), y por supuesto más que Brasil, paradigma de modelo que no ha entrado a este régimen de protección (posee 27 TBI, pero solo 1 en vigor: con Angola) (UNCTAD, 2020b). Actualmente la UNCTAD calcula en casi 2.902 TBI firmados en el mundo -aunque otros informes de Naciones Unidas los estiman en más de 3.200 (De Zayas, 2020)—, de los cuales 2.341 se encuentran vigentes (UNCTAD, 2020b). Si se observa la progresión de la celebración de estos tratados se observa que su mayor incremento se dio notablemente en la década de 1990 durante el auge del neoliberalismo económico, tanto en nuestro país como en la región y a nivel internacional.

Los argumentos más resonados en favor de la firma de estos tratados son que su firma motiva la atracción de las IED, otorgan una mayor seguridad jurídica al proteger las inversiones extranjeras, y que ello redundara en una mayor generación de trabajo, un mayor desarrollo para el país y una disminución de la pobreza. Según tales argumentos que motivaron la aprobación de estos acuerdos (argumentos que, dicho de paso, se siguen sosteniendo al día de hoy en boca de la mayoría de la dirigencia política, economistas de renombre y medios de comunicación), Argentina debería estar a la vanguardia de la seguridad jurídica y de la confianza para los inversionistas extranjeros. Sin embargo, el promedio de inversiones extranjeras sobre el PIB argentino es solamente del 2,28\% en los últimos 29 años, pues estamos cumpliendo tres décadas desde que nuestro país entró en este régimen jurídico.

Durante todo este tiempo solamente se vivió un único pico exponencial de inversión extranjera directa (IED) y fue un solo año (en treinta): 1999, a raíz de la privatización de YPF en manos de la multinacional española Repsol. El resto, los años en que las inversiones extranjeras estuvieron por encima del promedio fueron durante dos períodos. El primero, de 4 años (1997-2000), como último ciclo del proceso de privatizaciones iniciado con la presidencia de Carlos Menem. El segundo, de 8 años (2004-2012, con una caída en 2009 producto de la crisis económica internacional), paradójicamente durante un período en donde no se firmaron nuevos TBI y, no obstante, se evidenció el período de crecimiento económico más alto: mientras que en la década de 1989-1999 (década en la que se celebraron casi todos los TBI argentinos) el crecimiento rondó en un promedio de 3,6\%, en la década que va de 2003-2013 dicho índice indica un crecimiento promedio de 13,9\%; fue la época de los "superávits gemelos" (comercial y fiscal) y del crecimiento "a tasas chinas" (Banco Mundial, 2021). 


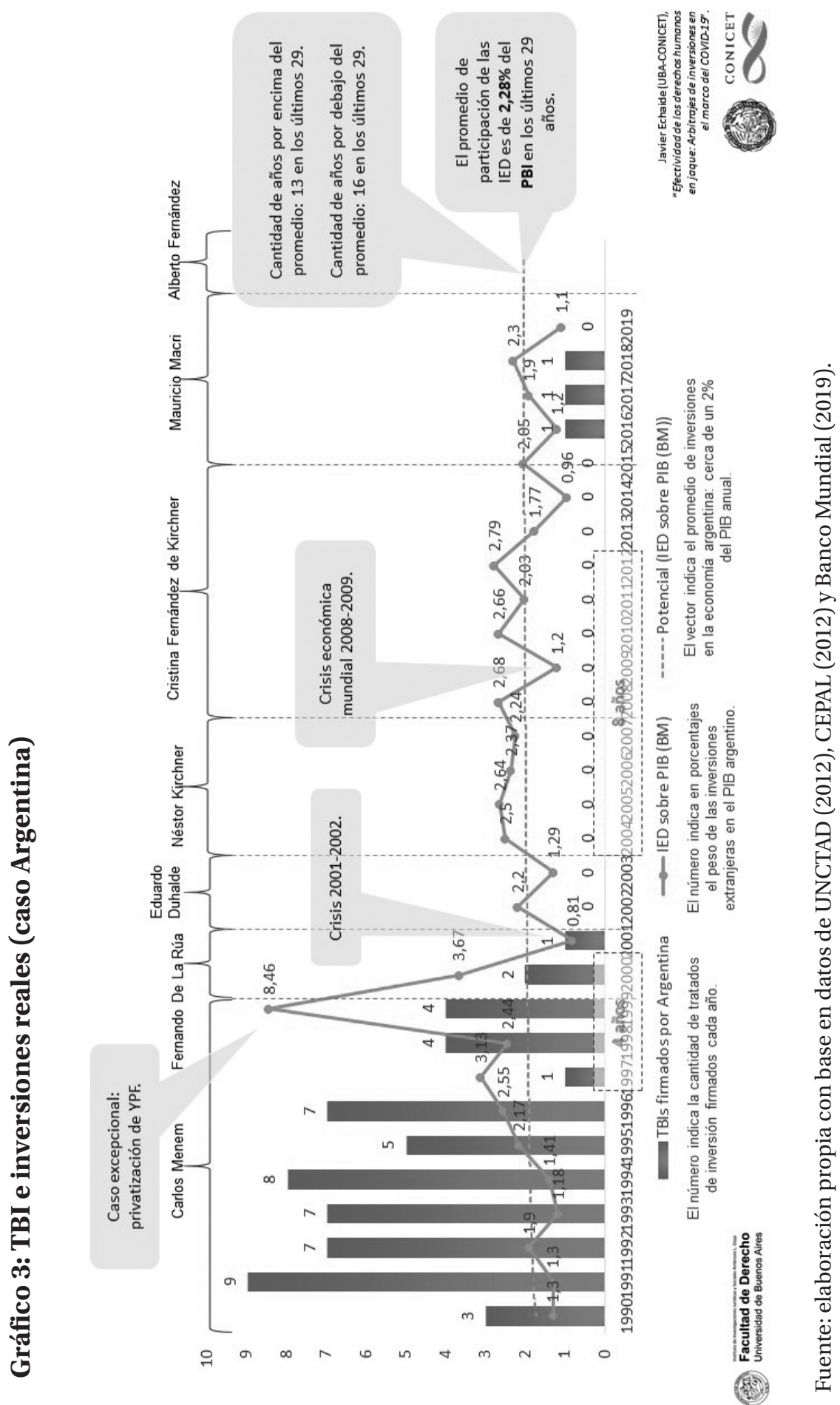


Por supuesto que un resultado no depende de un solo factor, y el crecimiento económico no puede depender solo de los TBI. Esta fue la conclusión a la que llegó la propia UNCTAD cuando en un informe publicado en 2009 admitió el que los TBI no resultaban ser un factor determinante para, siquiera, la atracción de inversiones (Ghiotto, 2017). A partir de ese momento la UNCTAD comenzó a revisar su propia política de promoción de los TBI y actualmente pide que se hagan sendas reformas a los mismos. Claro, lo dice tras los magros resultados obtenidos y luego de 15 años de haber sido una de las principales agencias internacionales que impulsaron ese modelo, a punto de organizar seminarios con decisores de gobierno entre países desarrollados y en desarrollo y a cuyo término se celebraban acuerdos masivos, todos bajo su auspicio.

La tesis sostenida de que los TBI atraerían inversiones y promoverían el desarrollo y el empleo se ha visto contradicha en los hechos. Si uno ve el paralelismo entre TBI e inversiones en Argentina, lo que se observa es precisamente la ausencia de relación. Pero lo mismo ocurre con el flujo de inversiones, los índices de pobreza, o el PBI per cápita. Pero, indudablemente, los TBI sí tienen una correlación con la cantidad de demandas internacionales, y esto es debido a que estos tratados poseen cláusulas que prorrogan la jurisdicción de los Estados en favor de tribunales de arbitraje internacionales y en favor de los inversionistas privados extranjeros (sean personas físicas como jurídicas, aunque por lo general se trata de empresas y de grandes capitales). Por lejos, el tribunal más acudido por las empresas para demandar a los Estados en materia de inversión es el Centro Internacional de Arreglos de Diferencias relativas a Inversiones (CIADI), perteneciente al Grupo del Banco Mundial. Ese organismo solo se lleva el 63\% de las demandas mundiales en la materia, y el $60 \%$ de dichas demandas se basan en alguna violación de algún TBI vigente (Bas Vilizzio, 2019; CIADI 2020a).

América Latina ha sido una de las regiones más afectadas en el mundo por este régimen de protección, no solamente por cantidad de demandas sino además por el monto de los casos. El monto total conocido de acuerdos de partes y de las demandas contra países latinoamericanos desde 1996 a 2019 asciende a US\$21.807 millones, lo que equivale al total de inversión extranjera directa que recibieron de manera combinada Argentina, Bolivia, Ecuador, Paraguay, Perú y Uruguay en el 2015 (TNI, 2019). Y hay otros montos que se desconocen: el problema de la transparencia de datos e información ha sido una constante desde hace décadas, dado que los tribunales arbitrales no están obligados a publicar los montos ni los laudos que emiten si las partes no están de acuerdo con ello. Por su lado, las bases de datos que recaban información —además de la dificultad mencionada- no coinciden en sus cifras, con lo cual las estimaciones resultan complejas y siempre debe hacerse esta salvedad al momento de arrojar números. 
Los actores intervinientes también se concentran en un número reducido: el $51 \%$ del total de casos en el CIADI ha sido resuelto por una combinación cruzada de tan solo 15 árbitros, mientras que en los casos contra países latinoamericanos los bufetes patrocinantes son solamente 13, al igual que las firmas de abogados que los han defendido. Entre todas ellas, 14 firmas son estadounidenses, 7 británicas, 3 argentinas y 1 ecuatoriana (TNI, 2019).

\section{La tormenta perfecta}

Argentina ostenta el triste récord de ser el Estado más demandado en la región -pero, además, en el mundo- ante el CIADI, con 62 casos históricamente registrados. En la región le siguen Venezuela (52), México (33), Ecuador (25), Perú (17) y Bolivia (17), para mencionar los cinco primeros países. El sistema de demandas inversor-Estado (conocido por sus siglas en inglés como ISDS) está siendo objeto de fuertes críticas desde al menos los últimos diez años y existen ya varias propuestas de reformas, incluso reconocidas por el propio organismo, pero sin implementarse (CIADI, 2021). Es que, si bien el CIADI es un organismo público creado en 1965 y con funcionamiento desde 1966, no recibió demandas hasta 1972 y durante 25 años el promedio de reclamos fue de 1,48 casos por año, es decir, una escala muy marginal. Fue a partir de la crisis económica de los denominados "Tigres Asiáticos" de 1997 - conocida como la "Gripe Asiática" - que el sistema comenzó a activarse, saltando durante los siguientes 6 años a un promedio de 12,66 demandas por año. La crisis de 2001 en Argentina motivó una importante cantidad de nuevos casos (43 casos, todos por los mismos hechos), lo que llevó incluso al CIADI a tener que contabilizar las demandas contra la Argentina como una categoría aparte del resto de las regiones del mundo. Si bien la avalancha de demandas contra Argentina fue una cuestión singular, no fue el único país demandado en ese contexto, y a escala mundial el promedio anual de casos ante el CIADI se duplicó. En 2011 y 2014 el sistema tuvo dos nuevos brotes de casos producto de la crisis financiera mundial de 2008 y la crisis española de 2014, llegando a un promedio de 48,3 demandas por año (ver Gráfico 4). El sistema opera de forma tal que la cantidad de demandas se incrementan como consecuencia de una crisis, pero no lo hacen de forma circunstancial, sino que aumentan en su cantidad, pero vuelven a disminuir una vez pasada la crisis. Al mismo tiempo, el tipo de demandas se ha diversificado cada vez más en cuanto a la clase de medidas gubernamentales atacadas por parte de las empresas, llevando a que el sistema sirva como una forma de cuestionar la legitimidad de las políticas públicas llevadas a cabo por los Estados soberanos (Bohoslavsky, 2010).

El presente año 2020 nos encuentra frente a una pandemia global por un nuevo virus hasta ahora desconocido: el coronavirus COVID-19. Ello resulta en una doble crisis provocada por la pandemia: una crisis sanitaria y otra económica. La 
crisis sanitaria es la primera crisis. Por lo que se conoce, el COVID-19 es un virus de alto grado de contagio, aunque baja tasa de mortalidad. La mayoría de los pacientes infectados que fallecen lo hacen por causas preexistentes que complican su cuadro clínico. Ello no obsta para que, debido a la gran cantidad de infectados que requieren internación con atención médica, los recursos hospitalarios disponibles (camas, personal profesional, respiradores y demás material) sean insuficientes y el sistema sanitario colapse. Requiere un alto grado de financiamiento público para el sostenimiento sanitario en esta emergencia, así como de los derechos humanos de la población, en particular los derechos económicos, sociales y culturales, incluyendo el derecho a la salud. 


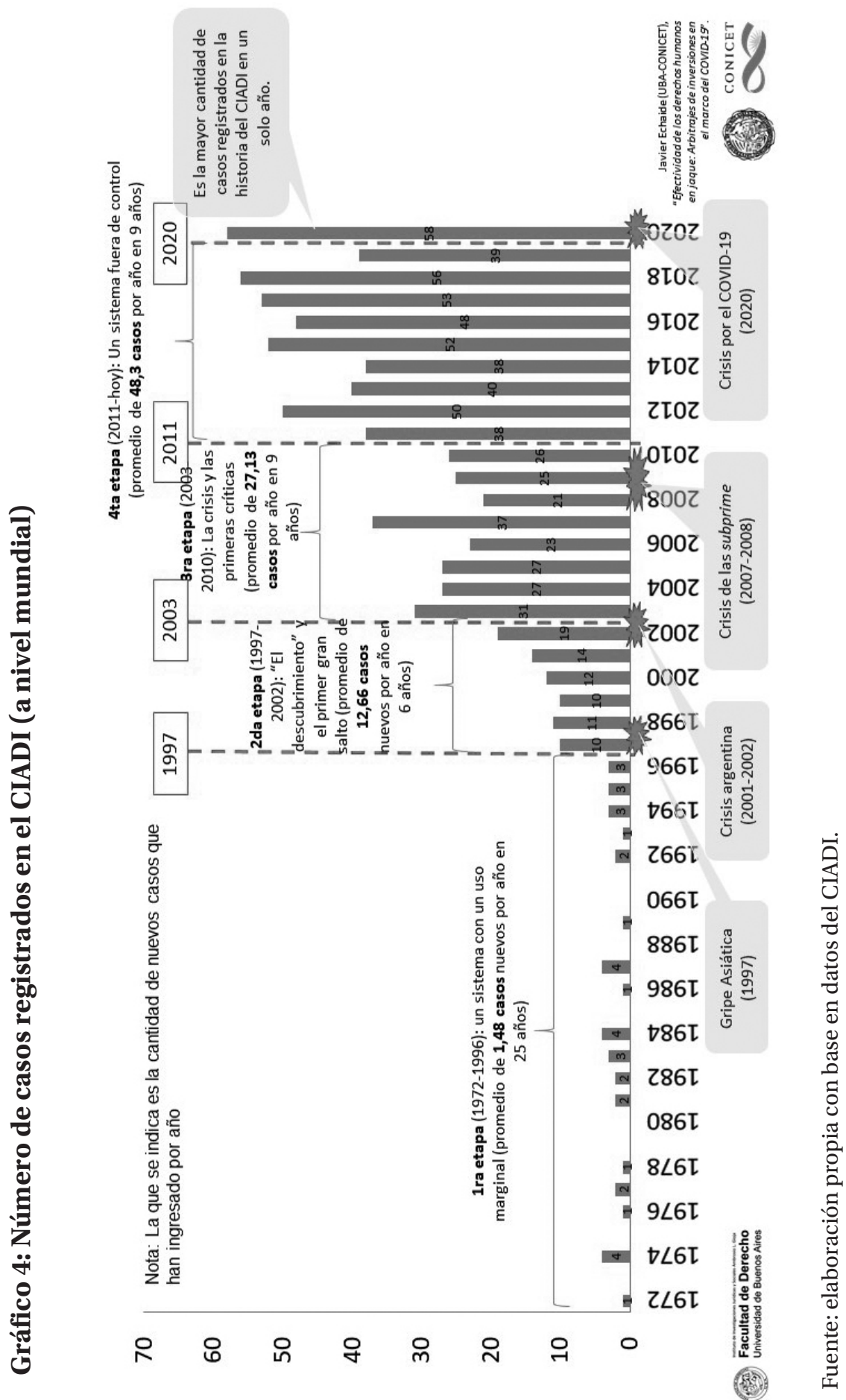


Pero la pandemia también lleva a una crisis económica. Se calculan hasta el momento (septiembre de 2021) más de cuatro millones doscientas mil personas fallecidas en todo el mundo, y más de 206 millones de personas contagiadas por el virus (Our World In Data, 2021) — cifras que se suman a las de otras enfermedades-. Esto implica un impacto en la economía por pérdida de trabajadores, caída de la productividad, pérdida de empleos, así como por las medidas llevadas a cabo para evitar una mayor propagación de la enfermedad. A mediados de abril de 2020 el FMI pronosticó una caída del PBI global en un -3\%. En mayo lo corrigió a un -4,9\%, en junio volvió a modificar su pronóstico a un $-5,2 \%$ y en octubre lo corrigió a un -4,4\% (FMI, 2020). Finalmente, calculó la recesión global del 2020 en un -3,3\% (FMI, 2021). Una crisis económica de tal magnitud implica sin ninguna duda una menor cantidad de recursos para actores privados, pero también para los públicos, lo cual hace que los Estados no puedan hacer frente a las necesidades sanitarias en el peor de los momentos, como tampoco pueda enfrentar las necesidades de empleo o de reactivación económica en sus territorios como resultado de la pandemia. Economías de países desarrollados caerían, según estos pronósticos, entre un $10 \%$ a un $12 \%$ (luego cayeron en un -4,7\% [FMI, 2021]), al tiempo que todas las tasas de crecimiento de las principales economías del mundo serían negativas, con la sola excepción de China, el único país que finalmente creció en un 2,3\%. El propio gobierno argentino ya calculó en el proyecto de Ley de Presupuesto que envió al Congreso Nacional que la caída del PBI será en un $-12 \%$ (cuando el FMI lo había calculado en un -9,9\% y que finalmente sería el número correcto). Estos números dramáticos se asimilan a la crisis de 2001, en donde el PBI nacional cayó a un (hasta ese momento) histórico -10,9\% (FMI, 2021). Se dijo, y con razón, que fue la peor crisis de nuestra historia. El JP Morgan pronosticó una caída del PBI de Argentina en un -13,2\%, mientras que el diario Perfil arriesgó un -15\% (Diario Perfil, 2020).

El panorama por venir se completa con otros datos que consultoras privadas ya adelantaron en el mes de junio: inflación de un 43,3\% anual, desempleo de un $13 \%$ y pobreza en un 45\% de la población (Revista Apertura, junio 2020).

El discurso globalizador parece reiterarse sin importar el clima. A estas alturas resulta poco convincente que los asesores económicos tengan una sola respuesta para una decena de escenarios diferentes. La integración librecambista de las economías puede multiplicar beneficios para sus principales actores económicos, pero también incrementan los riesgos, por lo que profundizar la integración comercial en esos términos en medio no solo de una recesión global sino además en una crisis internacional sin precedentes puede resultar algo cuanto mínimo temerario: ya la Organización Mundial del Comercio (OMC) pronosticó una caída del comercio mundial entre un $-13 \%$ a un $-32 \%$. Es un dato a considerar, por lo que una mayor volatilidad de capitales (sea por vía comercial como por vía de inversiones) no resultaría algo juicioso, ni siquiera para un pensamiento prolibremercado.

La crisis por el coronavirus es, pues, el escenario ideal para una tormenta perfecta. 


\section{Tres preguntas}

Como hemos visto, la experiencia de los últimos 50 años de funcionamiento del ISDS indica que tras cada crisis de envergadura — sea regional o global— las demandas por parte de empresas multinacionales se incrementan. Es de esperar que la crisis del COVID-19 sea un escenario ara un incremento importante de demandas tanto en el CIADI como en otros centros de arbitraje.

Tres preguntas pueden plantearse sin demasiada dificultad ante este escenario:

1) ¿Cómo terminará de impactar la crisis del COVID-19?

2) ¿Cómo actuarán las empresas transnacionales (ETN) ante la crisis económica causada por la pandemia global?

3) ¿Cómo actuarán los árbitros para juzgar los casos en este contexto?

La primera de ellas ya parece tener una respuesta: las empresas no han reparado en el contexto para demandar. Esto no es una hipótesis. En los primeros seis meses de 2020 ya se han presentado 40 demandas en el CIADI, y los países más demandados han sido Colombia y Perú (5 casos contra cada uno). Al finalizar el año se batió el récord histórico de demandas ante el CIADI, registrándose el pico de 58 demandas registradas en un solo año (CIADI, 2021) precisamente en el año de la pandemia global por COVID-19, con una crisis sanitaria mundial y con una recesión a igual escala. Una vez más, la crisis es el momento de auge de las demandas en el ISDS (ver Gráfico 4). América Latina fue la región más demandada en el primer semestre de 2020 (CIADI, 2020; CIAR Global, 2020). Además, algunos países de la región ya están siendo amenazados de ser demandados por medidas que han tomado en el marco de la pandemia con el objeto de evitar la expansión del virus y el aumento de contagios. Estas son algunas de las amenazas conocidas:

- Panamá por intentos de recisión de contrato por demoras de 5 años en la entrega de un hospital en construcción.

- Bolivia posiblemente sea ejecutada por falta de recursos humanos para la elaboración de documentación de defensa de sus casos de arbitraje. El gobierno ya lo manifestó en sus arbitrajes en curso y los árbitros rechazaron sus planteos.

- México fue amenazado por la suspensión de proyectos de energías renovables tras presionar a empresas extranjeras morosas en el cobro de impuestos.

- Perú y Argentina por suspensión del cobro de peajes en autovías y rutas a fin de evitar embotellamientos y aglomeración de personas.

- Argentina también reestructuró su deuda pública en medio de la pandemia (deuda que alcanzó el 86\% de su PBI). Tras el cambio de gobierno en diciembre 
de 2019 y a fin de hacer sustentable la continuidad de pagos, el acuerdo reestructuró US\$ 66.300 millones de deuda. Se acordó pagar 54,8 dólares por cada 100 (una cifra prácticamente equivalente al requerimiento de los bonistas y muy lejos de la oferta inicial del gobierno). Sin embargo, el fondo de inversiones Black Rock no acordó, insistiendo en su reclamo de recibir 56 dólares cada 100. Esta diferencia de US $\$ 2,20$ por bono puede causar una demanda internacional millonaria ante el CIADI, como ocurrió con el caso "Abaclat v. Argentina" por US\$ 1.350 millones. El mismo bufete de abogados que patrocinó en el caso Abaclat, asesora ahora a Black Rock: White \& Case.

- Colombia, Honduras, Paraguay y nuevamente Argentina han adoptado medidas de congelamiento de tarifas de servicios públicos durante la pandemia, incluyendo prohibiciones de corte de servicio por mora en la distribución de agua potable (esencial para el lavado de manos: primera medida sanitaria para prevenir el contagio de COVID-19).

- Guatemala suspendió el pago de laudos por falta de fondos en el marco de la pandemia (es el 2do país más pobre de América Latina). Ello ya está incurriendo en demandas por ejecución de dichos laudos.

- Chile está encarando la recisión de un contrato de provisión de agua potable y saneamiento con la multinacional francesa Suez por corte de suministro de agua durante una semana y la detección de bacterias fecales en la misma en la localidad de Osorno, en la Patagonia chilena.

- España fue amenazada también por la recisión de un contrato de suministro de agua potable en Cataluña (Olivet y Müller, 2020; TNI, 2020).

En casi todos los países del mundo se tomaron medidas que establecieron limitaciones significativas en materia de operaciones comerciales y sector productivo, acordando el cierre de negocios no esenciales. Muchos de estos proyectos productivos y negocios comerciales poseen capitales extranjeros que se encuentran protegidos por los TBI. Y cada uno de ellos puede constituir un riesgo de demanda contra el Estado que adoptó dichas medidas de restricción.

- Alemania, Israel y Canadá tomaron medidas para proteger la propiedad industrial en el ámbito sanitario y farmacéutico o en sectores relacionados, estableciendo licencias obligatorias.

- Estados Unidos tomó medidas relativas a la producción forzosa de material sanitario.

- Reino Unido adoptó medidas de prohibición u obstaculización de forma indirecta del reparto de dividendos. 
- Australia tomó medidas para la protección de la economía interior frente a inversiones extranjeras de compras de activos de riesgo.

- Italia, Irlanda y España tomaron medidas de nacionalización temporal de hospitales privados e incautación de material sanitario y/o relacionado a fin de lograr cubrir la demanda sanitaria durante la pandemia.

- Rusia, India y Ecuador adoptaron medidas de imposición de restricciones a la exportación de medicamentos y alimentos.

En oportunidades anteriores, casos en donde los derechos de propiedad de los inversionistas fueron objeto de litigios ante el CIADI y tuvieron que ver con cuestiones relativas a los derechos humanos, fueron los casos relacionados con la distribución de agua potable y saneamiento. Dentro de este tipo de casos, Argentina fue, una vez más, el país más demandado mundialmente en un total de nueve oportunidades. De esas nueve, en solo dos esa vinculación fue explícitamente reconocida: en el caso "Aguas Argentinas y otros c. Argentina", por la recisión del contrato de Aguas Argentinas a cargo de Suez (Caso CIADI ARB/03/19) y en el caso "Urbaser y otros c. Argentina" (Caso CIADI ARB $/ 07 / 26)$.

En el primero, el tribunal del CIADI admitió la presentación de varias ONG bajo la figura de amicus curiae, reconociendo que "podrían plantear una amplia gama de cuestiones complejas en materia de derecho público e internacional, incluidas consideraciones relativas a los derechos humanos", aunque el laudo final no receptó ninguna de esas consideraciones y condenó a la Argentina a pagar una indemnización de US\$ 405 millones a las transnacionales Suez (francesa), Vivendi (francesa también) y a Aguas de Barcelona (española).

El segundo caso planteó una discusión más profunda a raíz de la reconvención planteada por Argentina contra la empresa por violación al derecho humano al agua. En el laudo final, el tribunal del CIADI rechazó el planteo de Argentina entendiendo que la empresa no poseía obligaciones de ninguna clase bajo el marco del TBI Argentina-España de 1991. Sostuvo que las obligaciones en materia de derechos humanos por parte de las empresas inversionistas solamente podían constituir obligaciones de no hacer, es decir, de no interferencia (Echaide, 2018). Empero, el laudo final no arrojó un monto indemnizatorio dado que el tribunal laudó una violación de la garantía de propiedad de las inversiones, pero admitió el argumento de estado de necesidad planteado por el Estado argentino, aunque la condenó en el pago de costas por US\$ 1 millón.

Claramente a ninguno se le puede escapar que el contexto de la pandemia, si bien parece contribuir con la posibilidad real de una nueva oleada de demandas, también puede ayudar en argumentos que abonen en la defensa de las políticas llevadas a cabo por los distintos gobiernos en virtud de evitar una propagación aun mayor y consecuencias todavía más críticas. Así el argumento del estado de necesidad es el primero 
que, nuevamente, debería llegarnos a todos para ser utilizado: la decisión de producir un daño para evitar un mal todavía mayor. Pues para analizar las posibilidades de este argumento nuevamente el caso argentino puede servir de experiencia: de las 43 demandas que recibió en el marco de la crisis de 2001, en 14 oportunidades el Estado basó su defensa en el estado de necesidad. De esas 14 veces, en 11 el planteo fue rechazado por los tribunales arbitrales. El caso Urbaser fue uno de los tres casos en donde se aceptó.

Lo cierto es que el sistema se basa en el case-law generado por tribunales ad hoc. Por eso es que los estudios sobre esta materia se encuentren plagados de análisis casuísticos en vez de análisis sistémicos, y por eso es también que permanentemente unos laudos citen a otros previos, aunque hayan sido decididos por tribunales diferentes y aunque el stare decisis - tan característico del common law - no sea un criterio aplicable dentro del derecho internacional. Y no obstante todos estos "peros", los tribunales mantienen esa forma de operar sin demasiados cuestionamientos internos(1).

\section{Cuando los derechos humanos dependen de los recursos}

La dependencia de los derechos a cuestiones económicas es algo que quiebra la igualdad de quienes deben gozarlos. Tal como lo sostuvo Paine hace casi dos siglos y medio, esa dependencia hace a la precariedad de tales derechos y, en consecuencia, de las condiciones de quienes los detentan. Pero también resulta evidente que sostener los derechos implica costos y, con ello, el compromiso económico por parte del Estado y de los y las ciudadanos/as que formamos parte de la sociedad que los sufraga mediante el pago de impuestos. Si el pensamiento liberal más amplio admite que los derechos implican un costo, entonces fortalecer el erario público es el primer paso para tener con qué ir por más y mejores derechos, no menos.

Si los actos de corrupción son entendidos de manera sencilla como escuelas que no han de construirse ante un ataque a los recursos públicos que implica una malversación de fondos, ¿ipor qué las demandas masivas provenientes del sector privado en materia de inversiones no son vistas como un ataque a la posibilidad de robustecer

(1) En términos recientes, una excepción quizás pueda ser la siguiente: "A mí me impresiona el cúmulo de latinoamericanos que uno encuentra en el camino del arbitraje, gente muy sólida, gente joven que está dentro de una dinámica de pertenecer a un esquema que fue novedoso cuando fue mi época, en 1990 [al] entrar en este sistema, hoy es uno de los temas más importantes que preocupan a los que estudian Derecho y Derecho de las Inversiones. Y finalmente creo que hay algo que nos falta a todos que es una autocrítica escrita, lanzarnos a escribir para fijar posiciones en distintos temas; cuando un caso no nos gusta, el decir por qué no nos gusta. Pero el problema es que estamos autolimitados, autocensurados porque el hecho de escribir y de firmar un artículo en donde decimos algo implica dejarnos de lado para futuros arbitrajes" (Vinuesa, 2020). Recuperado de https://www.youtube.com/watch?v=TQyN_FBqlas\&list=RDCMUCyeHXK8kPsCyseQUIDEHaZQ\&s tart_radio=1\&t=3863\&ab_channel=DerechoUBA [Fecha de consulta: octubre de 2020]. 
el sistema sanitario en tanto también resultan un ataque a los recursos públicos que podrían destinarse a la compra de vacunas y la defensa de los sistemas públicos de salud, máxime en su momento de mayor necesidad como es una pandemia? El derecho a la salud es un derecho humano básico y universal. El derecho al agua también lo es. Ambos son el vértice en este contexto del cuidado y de la lucha contra este nuevo virus que resulta mortal no tanto por su letalidad sino por su propagación: al ser altamente contagioso hace colapsar los sistemas sanitarios que simplemente no pueden responder ante la cantidad de enfermos. Y esto es peor en localidades pequeñas. Existen dos recursos que resultan esenciales para la lucha contra el virus y son el tiempo y el dinero. Algo de tiempo puede lograrse mediante el cumplimiento de medidas adoptadas para reducir la propagación de la enfermedad. Pero si esas medidas han de ser atacadas por las empresas privadas extranjeras que pudieran sentirse afectadas, los Estados se verán una vez más en la posición de elegir entre adoptarlas y enfrentarse a ser demandados o rendirse ante el poder de la disuasión, perjudicando a la población en general para la preservación de los derechos de propiedad de uno. Es una nueva versión de lo que en el sistema de inversiones ya se ha llamado chilling effect o "enfriamiento regulatorio", y constituye en la autoinhibición del Estado al momento de regular para no verse en situación de ser demandado por una empresa inversionista, lo que deriva en una pérdida del espacio regulatorio del Estado y con ello de su poder de policía. De nuevo: la razón de Estado puesta en jaque. Pero no solo es el Estado que ve disminuido su poder de acción, sino que son los derechos de la población los que pueden verse indirecta ( $\mathrm{y}$ a veces directamente) atacados en pos de los intereses de actores poderosos en este escenario global en donde el capital privado transnacional se mide de igual a igual con muchos Estados.

\section{Conclusiones}

Algunas conclusiones pueden adelantarse:

La crisis originada por el coronavirus implicará un aumento significativo de demandas dentro del sistema ISDS. La naturaleza de dichas demandas es plural y abarca todo sector sobre el cual un Estado ha tomado medidas de restricción en el marco de la pandemia.

El aumento de demandas profundiza la crisis causada por la pandemia en tanto implica además una transferencia de recursos de manos públicas a manos privadas.

Ya no son pocas las voces que reclaman por una moratoria de demandas bajo el ISDS. Sin embargo, ante el apremio de las demandas que ya se han presentado, una posible suspensión motivada en esta emergencia mundial no es algo previsible, como tampoco lo es una aceleración de las reformas en debate. Ello sustentará en un aumento de las críticas al sistema de protección de inversiones bajo la figura de inversorEstado o ISDS. 
Si bien las demandas no habrán de constituir un compromiso del erario público de los distintos países demandados a corto plazo (pues los arbitrajes suelen demorar varios años hasta concluirse), sí pueden resultar en una falta de financiamiento a mediano plazo y con ello deteriorar el sostenimiento de derechos humanos y sociales básicos ante la pandemia global, lo cual prolongará la crisis e incrementará la desigualdad.

Uno de los aspectos que incide en la desigualdad es el derecho internacional de las inversiones extranjeras. Si entendemos que la desigualdad es un problema, entonces difícil es negar que los aspectos que inciden en ella también lo son.

\section{Bibliografía}

AA.VV. El País que Espera Después de la Pandemia (Dossier) (2020). Revista Apertura. Número de junio 2020 (pp. 20-78).

Arroyo Picard, A. y Ghiotto, L. (2017). Brasil y la nueva generación de Acuerdos de Cooperación y Facilitación de Inversiones: un análisis del Tratado con México. Revista Relaciones Internacionales. Vol. 26, №. 52. La Plata: Universidad Nacional de La Plata. Recuperado de: http://www.scielo.org.ar/scielo.php?pid=S2314-27662017000100003 \&script=sci_arttext\&tlng=es [Fecha de consulta: septiembre 2021].

Banco Mundial (2021). Crecimiento del PIB (\% anual) - Argentina. Recuperado de: https://datos.bancomundial.org/indicator/NY.GDP.MKTP.KD.ZG?locations=AR [Fecha de consulta: septiembre 2021].

Bas Vilizzio, M. (2019). Estado-empresas transnacionales: cambios en régimen de solución de controversias inversor-Estado y redefinición de la soberanía a la luz de la protección de los derechos humanos (Tesis Doctoral). La Plata: Universidad Nacional de La Plata.

Bohoslavsky, J. P. (2010). Tratados de protección de las inversiones e implicaciones para la formulación de políticas públicas (especial referencia a los servicios de agua potable y saneamiento). Santiago de Chile: Comisión Económica para América Latina y el Caribe (CEPAL). Recuperado de: https://www.cepal.org/es/publicaciones/3769tratados-proteccion-inversiones-implicaciones-la-formulacion-politicas-publicas [Fecha de consulta: septiembre 2021].

CIADI (2021). Carga de casos en el CIADI - Estadísticas Edición 2021-2. Recuperado de: https://icsid.worldbank.org/sites/default/files/Caseload\%20Statistics\%20 Charts/The\%20ICSID\%20Caseload\%20Statistics\%202021-2\%20Edition-SPA.pdf [Fecha de consulta: septiembre 2021].

CIADI (2020). Propuesta de enmiendas a las Reglas del CIADI. Recuperado de. https://icsid.worldbank.org/sites/default/files/amendments/WP_4_Vol_3_Sp.pdf [Fecha de consulta: octubre 2020]. 
CIAR Global (2020). Sudamérica, región más demandada en arbitraje de inversiones. CIADI. Recuperado de: https://ciarglobal.com/america-del-sur-region-mas-demandada-en-arbitraje-de-inversiones-en-ciadi/?fbclid=IwAR1RM7-5r6jvFm6f4za6idHCDKFUfZMCYiOUgPTAO2yLku-vqeaT83lhwPg [Fecha de consulta: septiembre 2021].

Confederación Sindical Internacional (2020). Lo que realmente importa: Medir la rendición de cuentas gubernamental e ir más allá del PIB. Informe de la Campaña Nuevos Frentes de la CSI Democracias para las personas. Recuperado de https://www. ituc-csi.org/IMG/pdf/measuring_government_accountability_and_moving_beyond_gdp_es.pdf [Fecha de consulta: abril 2021].

Credit Suisse (2019). The Global wealth report. Recuperado de https://www.creditsuisse.com/fi/en/articles/media-releases/global-wealth-report-2019--globalwealth-rises-by-2-6--driven-by-201910.html [Fecha de consulta: octubre 2020].

DeZayas, A. (2015). Informe del Experto Independiente sobre la promoción de un orden internacional democrático y equitativo, Consejo de Derechos Humanos ONU. Recuperado de: https://undocs.org/es/A/HRC/30/44 [Fecha de consulta: octubre 2020].

Echaide, J. (2018). El derecho humano al agua potable y los tratados de protección recíproca de inversiones. Buenos Aires: Facultad de Derecho UBA. Thomson ReutersLa Ley.

Estévez Araujo, J. A. (2021). Las transformaciones jurídicas de la globalización neoliberal. En J. A. Estévez Araujo, El derecho ya no es lo que era. Las transformaciones jurídicas en la globalización neoliberal (pp. 69-122). Madrid: Trotta.

FMI (2020). Informes de Perspectivas de la Economía Mundial - Octubre de 2020. Recuperado de: https://www.imf.org/es/Publications/WEO/Issues/2020/09/30/ world-economic-outlook-october-2020 [Fecha de consulta: septiembre 2021].

FMI (2021). Real GDP growth. Recuperado de: https://www.imf.org/external/datamapper/NGDP_RPCH@WEO/OEMDC/ADVEC/WEOWORLD [Fecha de consulta: septiembre 2021].

Ghiotto, L. (2017). ¿UNCTAD pro-desarrollo o pro-liberalización? Un estudio de los cambios en el organismo a la luz de las políticas sobre inversiones. En J. Echaide, Inversiones extranjeras y responsabilidad social de las empresas; problemáticas en torno al CIADI, los TBI y los Derechos Humanos (pp. 53-78). Buenos Aires: Ediciones BdeF.

Holmes, S. y Sunstein, C. (2011). El costo de los derechos. Por quéla libertad depende de los impuestos. Buenos Aires: Siglo XXI.

Kelly, P. (2014). El Libro de la Política. Londres y Madrid: DK \& Akal. 
Olivet, C. y Müller, B (2020). Haciendo malabares: América Latina entre la crisis de la pandemia y el arbitraje de inversiones. Amsterdam: Transnational Institute (TNI). Recuperado de: https://longreads.tni.org/es/isds-covid19-alc [Fecha de consulta: septiembre 2021].

Our World In Data (26/09/2021a). Casos acumulados confirmados de COVID-19. Recuperado de: https://ourworldindata.org/covid-cases [Fecha de consulta: septiembre 2021].

Our World In Data (26/09/2021b). Muertes acumuladas confirmadas por COVID-19. Recuperado de: https://ourworldindata.org/covid-deaths [Fecha de consulta: septiembre 2021].

Perfil (12/07/2020). El derrumbe será inédito. Recuperado de: https://www. perfil.com/noticias/medios/tapa-diario-perfil-domingo-12-julio-2020.phtml $\# \mathrm{lg}=1 \&$ slide $=0$ [Fecha de consulta: octubre 2020].

TNI (2014). Estado del Poder 2014. Recuperado de: https://www.facebook.com/ TransnationalInstitute/photos/a.685763768142066/685764334808676/?type=3\&thea ter [Fecha de consulta: octubre 2020].

TNI (2019). ISDS en Números. Recuperado de: https://www.tni.org/files/publication-downloads/isds_en_numerosesapril2019_-final.pdf [Fecha de consulta: octubre 2020].

TNI (2020). ISDS y Covid-19. Recuperado de: https://isds-americalatina.org/isdsy-covid-19/ [Fecha de consulta: septiembre 2021].

UNCTAD (2020a). Investment Policy Hub. Recuperado de https://investmentpolicy.unctad.org/international-investment-agreements/countries/8/argentina [Fecha de consulta: octubre 2020].

UNCTAD (2020b). Investment Policy Hub. Recuperado de https://investmentpolicy.unctad.org/international-investment-agreements [Fecha de consulta: octubre 2020].

Vinuesa, R. (2020). El arbitraje de inversión: desafíos para América Latina (minuto 37:52). Buenos Aires: Facultad de Derecho (UBA). Recuperado de: https://www.youtube.com/watch?v=TQyN_FBqlas\&list=RDCMUCyeHXK8kPsCyseQUlDEHaZQ\&sta rt_radio=1\&t=3863\&ab_channel=DerechoUBA

Fecha de recepción: 17-03-2021

Fecha de aceptación: 12-10-2021 